\title{
Development of a Modified Korean East Asian Student Stress Inventory by Comparing Stress Levels in Medical Students with Those in Non-Medical Students
}

\author{
Hee Kon Shin, Seok Hoon Kang*, Sun-Hye Lim, Jeong Hee Yang, Sunguk Chae \\ Department of Family Medicine Kangwon National University Hospital, Chuncheon, Korea
}

\begin{abstract}
Background: Medical students are usually under more stress than that experienced by non-medical students. Stress testing tools for Korean medical students have not been sufficiently studied. Thus, we adapted and modified the East Asian Student Stress Inventory (EASSI), a stress testing tool for Korean students studying abroad, and verified its usefulness as a stress test in Korean university students. We also compared and analyzed stress levels between medical and non-medical students.

Methods: A questionnaire survey was conducted on medical and non-medical students of a national university, and the responses of 224 students were analyzed for this study. Factor analysis and reliability testing were performed based on data collected for 25 adapted EASSI questions and those on the Korean version of the Global Assessment of Recent Stress Scale (GARSS). A correlation analysis was performed between the 13 modified EASSI questions and the GARSS, and validity of the modified EASSI was verified by directly comparing stress levels between the two student groups.

Results: The 13 questions adapted for the EASSI were called the modified EASSI and classified into four factors through a factor analysis and reliability testing. The Pearson's correlation analysis revealed a significant correlation between the modified EASSI and the Korean version of the GARSS, suggesting a complementary strategy of using both tests.

Conclusion: The validity and reliability of the EASSI were verified. The modified Korean EASSI could be a useful stress test for Korean medical students. Our results show that medical students were under more stress than that of non-medical students. Thus, these results could be helpful for managing stress in medical students.
\end{abstract}

Keywords: Medical Students; Stress; Stress, Psychological 


\section{INTRODUCTION}

The academic stress of medical students is expected to be greater than that of other college students because of frequent testing, the overwhelming amount of studying required, ${ }^{1)}$ and the active flunk-out system, which is rare in other courses. ${ }^{2)}$ Medical students do not use appropriate tools to manage or react to stressors, ${ }^{3)}$ and chronic severe stress decreases concentration, attention, decision-making, and the ability to establish future relationships between patients and physicians. ${ }^{4)}$

Various medical stress tests have been developed by Vitaliano et al. ${ }^{5)}$ and Dahlin et al. ${ }^{6)}$ are applied in the daily lives of medical students in other countries. However, most stress tests have been adapted and used in South Korea based on those developed for other countries, so no stress test has been verified for use in South Korea except that created by Kim et al. ${ }^{7)}$

For this study, we selected the East Asian Student Stress Inventory (EASSI) which is known for considering Korean students at the development stage. We directly translated EASSI to include Korean students, modified some of the items, and verified their use statistically. The objective of this study was to verify the utility of this modified EASSI.

\section{METHODS}

\section{Subjects}

Questionnaire surveys were conducted from August 1 to September 10, 2014 with all first and second grade medical students

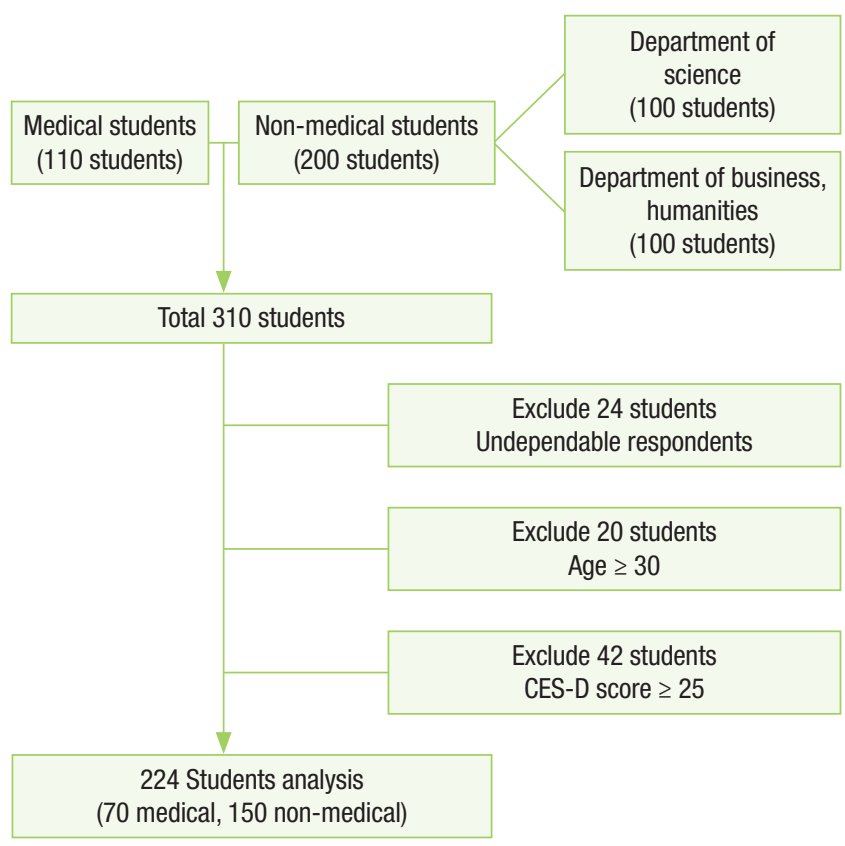

Figure 1. Trial profile. Questionnaire responses from 224 subjects were complete. Twenty-four respondents did not complete the questionnaire, 20 were 30-40 years old, and 42 had a depression index on the Korean Center for Epidemiologic Studies Depression (CES-D) Scale $>25$ points. $(\mathrm{n}=110)$, randomly selected first and second grade non-medical students $(n=100)$ from a science college, and randomly chosen students $(n=100)$ from the business and humanities schools at a university located at Chuncheon, Gangwondo, South Korea. The completed questionnaires were collected after the respondent self-reported their answers. A total of 224 subjects completed the questionnaire. Twenty-four students who did not complete the questionnaire, 20 respondents $30-40$ years old, and 42 subjects with a depression index score $>25$ on the Korean Center for Epidemiologic Studies Depression (CES-D) Scale were excluded (Figure 1).

\section{Survey Tools}

\section{1) Adapted the East Asian Student Stress Inventory}

EASSI is a verified tool developed by Chng et al. ${ }^{8}$ in 1998 and is used to measuring student stress in 11 Asian countries including Korea. We adapted the original English EASSI consisting of 31 questions. Six questions unsuitable for Korean culture were excluded and only 25 questions were used for this study.

The questionnaire was scored on a 5-point Likert scale with 1 point indicating 'do no agree' and 5 points indicating 'agree completely. Thus, higher scores indicate more stress.

\section{2) Korean Global Assessment of Recent Stress Scale}

Similar to the cognitive awareness scale published by Koh et al. ${ }^{9}$ in 2000, the Korean Global Assessment of Recent Stress Scale (GARSS) is a tool to evaluate the stress recognition response using eight questions. Responses are recorded on a 9-point Likert scale from 0 points indicating 'never' to 9 points indicating 'extremely serious.' Thus, higher scores indicate more stress.

\section{3) Korean Center for Epidemiologic Studies Depression}

The reliability and validity of the Korean CES-D was verified by Cho et al. ${ }^{10)}$ in 1993. Higher scores indicate a greater degree of depression.

\section{Analytical Methods}

Subjects who scored $>25$ points on the Korean CES-D were excluded from the analysis because a higher depression index means more stressful conditions. ${ }^{11)}$ A Varimax rotation factor analysis was conducted after performing the Bartlett and Kaiser-Meyer-Olkin (KMO) sample suitability tests to verify internal construct validity of the 25 questions for the adapted EASSI. Thirteen questions with four factors were selected through factor analysis and were called the modified EASSI. Reliability of the fours factors for the modified EASSI was verified using Cronbach's alpha. Pearson's correlation coefficient analysis was used to identify the relationship between the stress indices in the modified EASSI and Korean GARSS. 


\section{RESULTS}

\section{Sociodemographic Characteristics}

The sociodemographic characteristics of the subjects are described in Table 1. Only 20-29 year old subjects were included in this study. Seventy-four (42 males and 32 females) medical students and 150 (114 males and 36 females) non-medical students were included. The students included 106 first-grade students (35 medical and 71 non-medical) and 118 second-grade students (39 medical and 79 non-medical).

\section{Factor and Reliability Analyses}

The Bartlett and KMO sample suitability tests were conducted to determine the suitability of the responses to the adapted questions in the EASSI for the factor analysis. The results were 0.838 for KMO sample suitability, an approximate chi-square of 2,160.771, 300 degrees of freedom, and a $\mathrm{P}<0.001$, indicating that responses were suitable for a factor analysis.

Varimax rotation using $>1.0$ point eigenvalues yielded six factors from the 25 adapted EASSI questions. Questions were deleted in cases of factor loading $<0.4$ in one factor, $>0.4$ in two factors, and combined questions with uncorrelated factors. Finally, 13 questions were selected by removing questions and

Table 1. Sociodemographic data

\begin{tabular}{lcc}
\hline Variable & Medical student & Non-medical student \\
\hline Sex & & \\
Male & $42(57)$ & $114(76)$ \\
Female & $32(43)$ & $36(24)$ \\
Grade & & \\
First & $35(47)$ & $71(47)$ \\
Second & $39(53)$ & $79(53)$ \\
Total & $74(100)$ & $150(100)$
\end{tabular}

Values are presented as number (\%).

Table 2. Factor loading for the modified East Asian Student Stress Inventory

\begin{tabular}{lcrrr}
\hline \multirow{2}{*}{ Question } & \multicolumn{4}{c}{ Factor $^{\star}$} \\
\cline { 2 - 5 } & 1 & 2 & \multicolumn{1}{c}{3} & \multicolumn{1}{c}{4} \\
\hline 1 & 0.820 & 0.090 & -0.069 & 0.080 \\
2 & 0.814 & -0.059 & 0.078 & -0.080 \\
3 & 0.803 & 0.116 & 0.169 & 0.040 \\
4 & 0.738 & 0.029 & -0.063 & 0.113 \\
5 & 0.519 & 0.256 & -0.465 & 0.060 \\
1 & 0.114 & 0.815 & 0.200 & 0.020 \\
2 & 0.114 & 0.807 & -0.014 & 0.197 \\
3 & -0.009 & 0.779 & 0.100 & 0.038 \\
4 & 0.034 & 0.639 & 0.342 & 0.271 \\
1 & 0.259 & 0.293 & 0.756 & 0.085 \\
2 & -0.121 & 0.264 & 0.728 & 0.245 \\
1 & 0.151 & 0.103 & 0.011 & 0.849 \\
2 & -0.026 & 0.194 & 0.269 & 0.756 \\
Cronbach's $\alpha$ & 0.807 & 0.809 & 0.643 & 0.594
\end{tabular}

Kaiser-Meyer-Oklin =0.809, Bartlett $=954.341(\mathrm{df}=78, \mathrm{P}<0.001)$.

*Factor 1: grade and test stress, 2: physiological stress, 3: leisure life-related stress, 4: personal relationship stress factors with low Cronbach's alpha values.

The KMO sample suitability value was 0.809 for the 13 questions in the modified EASSI composed, the approximate chisquare was 954.341 with 78 degrees of freedom and a $\mathrm{P}<0.001$, indicating suitability for the factor analysis. Four factors extracted from the Varimax rotation under conditions of $>1.0$. Eigenvalue point explained $66.60 \%$ of the total variance. Factor 1 (five questions) explained $22.51 \%$ of the variance and was classified as a grade and test stress item. Factor 2 (four questions) explained $20.20 \%$ of the variance, factor 3 (two questions) explained $12.32 \%$ of the variance, and factor 4 (two questions) explained $11.58 \%$ of the variance and were classified as 'physiological stress,' 'stress related to leisure life,' and 'personal relationship stress,' respectively. The Cronbach's alpha value for the 13 modified EASSI questions was 0.80 . Factor 1 reliability was 0.807 , that for factor 2 was 0.809 , that for factor 3 was 0.643 , and that for factor 4 was 0.594 (Table 2).

\section{Correlation between the Modified East Asian Student} Stress Inventory and the Korean Global Assessment of Recent Stress Scale

A moderate positive correlation was observed $(\mathrm{r}=0.463, \mathrm{P}<0.001)$ between the modified EASSI and Korean GARSS scores.

\section{Comparison of Stressors between the Two Student Groups Using the Modified East Asian Student Stress Inventory and Korean Global Assessment of Recent Stress Scale}

The mean scores of the medical students on the modified EASSI and Korean GARSS were significantly higher than those of

Table 3. Differences in the modified EASSI and GARSS scores between the two groups

\begin{tabular}{clcccc}
\hline Test & Value & $\begin{array}{c}\text { Medical } \\
\text { student }\end{array}$ & $\begin{array}{c}\text { Non-medical } \\
\text { student }\end{array}$ & t-value & P-value $^{\dagger}$ \\
\hline Modified & No. & 74 & 150 & $3.835^{*}$ & $<0.001$ \\
EASSI & Mean \pm SD & $36.96 \pm 7.44$ & $32.28 \pm 7.14$ & & \\
GARSS & No. & 74 & 150 & $7.009^{*}$ & $<0.001$ \\
& Mean \pm SD & $31.7 \pm 12.87$ & $18.25 \pm 13.81$ & & \\
\hline
\end{tabular}

EASSI, East Asian Student Stress Inventory; GARSS, Global Assessment of Recent Stress Scale; SD, standard deviation.

${ }^{*} \mathrm{P}<0.05$. 'From t-test after comparing the two groups.

Table 4. Differences in the modified East Asian Student Stress Inventory scores (four factors) between the two groups

\begin{tabular}{llcccc}
\hline Factor & \multicolumn{1}{c}{ Value } & $\begin{array}{c}\text { Medical } \\
\text { student }\end{array}$ & $\begin{array}{c}\text { Non-medical } \\
\text { student }\end{array}$ & t-value & P-value $^{\dagger}$ \\
\hline Grade/test & No. & 74 & 105 & $3.494^{*}$ & 0.001 \\
& Mean \pm SD & $18.54 \pm 3.48$ & $16.49 \pm 4.51$ & & \\
Physiologic & No. & 74 & 105 & $4.507^{*}$ & $<0.001$ \\
& Mean \pm SD & $9.76 \pm 3.84$ & $7.51 \pm 3.33$ & & \\
Leisure life & No. & 74 & 105 & $-0.686^{*}$ & 0.49 \\
& Mean \pm SD & $3.80 \pm 1.48$ & $3.95 \pm 1.66$ & & \\
Personal & No. & 74 & 105 & $2.514^{*}$ & 0.01 \\
relationship & Mean \pm SD & $5.18 \pm 1.75$ & $4.56 \pm 1.71$ & & \\
\hline
\end{tabular}

$\mathrm{SD}$, standard deviation.

${ }^{\star} \mathrm{P}<0.05$. ${ }^{\dagger}$ From t-test after comparing the two groups. 
non-medical students (Student t-test, $\mathrm{P}<0.05$ ) (Table 3). The mean scores of the medical students for the three factors of 'grade and test stressors,' 'physiological stress,' and 'personal relationship stress' on the modified EASSI were significantly higher than those of the non-medical students. The mean scores of the non-medical students tended to be higher for the 'stress related to leisure life' factor on the modified EASSI than those of the medical students $(\mathrm{P}>0.05)$ (Table 4$)$.

\section{DISCUSSION}

The medical school practice of frequent testing and too much studying can cause serious stress and the depression in students. ${ }^{12)}$ Korean medical students are expected to undergo much more stress than that of non-medical students. We attempted to develop a stress test tool that can be used easily by medical students. The target population of this study was restricted to first- and second-grade students because the education style for medical students is similar to that of non-medical students in these grades. Third- and fourth-grade medical students usually receive a unique apprenticeship education in a teaching hospital.

The medical students suffered more severe stress than that of the non-medical students on the factors 'grade and test stressors' and 'personal relationship stress' measured by the modified EASSI. This result suggests that medical students are driven to serious competition through frequent testing and the eternal leave policy compared those of other students.

The 'physiological stress' factor is connected to various physical pathologies and increases physiological symptoms, such as headache, gastric cramps, and fatigue ${ }^{13)}$ Medical students scored higher on this factor than non-medical students $(\mathrm{P}<0.001)$, so that the student manager at the medical school or at the medical specialty graduate school must recognize this situation and establish an appropriate plan to ensure student health.

No difference was observed between medical and non-medical students for the 'stress related to leisure' factor. This result was unexpected, considering the harsh environment of medical school and the limited vacation period. However, this result suggests that non-medical students can't enjoy vacation to develop skills or work part-time jobs, even though they have a relatively longer break than that of medical students.

A moderate positive correlation was observed between of the modified EASSI and Korean GARSS scores. This result seemed to originate from the differences in target range between the modified EASSI, which contains mostly academic questions related to college life and the GARSS, which measures general stress related to school and personal relationships. Thus, a combined method with both tests is recommended to accurately measure college student stress in the future.

It is difficult to generalize our results, as we included college students and students of medical specialty graduate school not a school college, who are in their 20s. Moreover, we only selected 13 questions and excluded 12 questions from the 25 questions on the adapted EASSI. Errors in the adapting procedure or misinterpretation of the self-reporting questionnaire may have occurred.

The modified EASSI consisted of 13 questions on four factors and was applicable as a tool to measure stress for Korean medical school, medical specialty graduate school, or general college students. The modified EASSI could be effective to manage stressors in these students in the future.

\section{CONFLICT OF INTEREST}

No potential conflict of interest relevant to this article was reported.

\section{REFERENCES}

1. Park JS, Ryu SY, Jang EJ, Kim JB. The effects of anxiety and ego strength on stress coping styles in the medical students. J Korean Soc Biol Ther Psychiatry 2002;8:150-7.

2. Kim SH, Jeon WT. The failure experiences of medical school students: a qualitative study. Korean J Med Educ 2008;20:351-62.

3. Lee KH, Ko Y, Kang KH, Lee HK, Kang J, Hur Y. Mental health and coping strategies among medical students. Korean J Med Educ 2012;24:5563.

4. Shapiro SL, Shapiro DE, Schwartz GE. Stress management in medical education: a review of the literature. Acad Med 2000;75:748-59.

5. Vitaliano PP, Russo J, Carr JE, Heerwagen JH. Medical school pressures and their relationship to anxiety. J Nerv Ment Dis 1984;172:730-6.

6. Dahlin M, Joneborg N, Runeson B. Stress and depression among medical students: a cross-sectional study. Med Educ 2005;39:594-604.

7. Kim MJ, Park KH, Yoo HH, Park IB, Yim J. Development and validation of the medical student stress scale in Korea. Korean J Med Educ 2014; 26:197-208.

8. Chng CL, Ding J, Perez MA. Validation of the East Asian Student Stress Inventory (EASSI). Am J Health Stud 1998;14:153-60.

9. Koh KB, Park KJ. Validity and reliability of Korean version of the global assessment of recent stress scale. Korean J Psychosom Med 2000;8:20111.

10. Cho MJ, Kim HK. Diagnostic validity of the CES-D (Korean version) in the assessment of DSM-III-R major depression. J Korean neuropsychiatry Assoc 1993;32:381-99.

11. Lee KH, Ko Y, Kang KH, Lee HK, Kang J, Hur Y. Mental health and coping strategies among medical students. Korean J Med Educ 2012;24:5563.

12. Guthrie EA, Black D, Shaw CM, Hamilton J, Creed FH, Tomenson B. Embarking upon a medical career: psychological morbidity in first year medical students. Med Educ 1995;29:337-41.

13. Lee EH. Life stress and depressive symptoms among college students: testing for moderating effects of coping style with structural equations. Korean J Health Psych 2004;9:25-52. 